\title{
The Will Rogers phenomenon, Breast Cancer and Race
}

\author{
Mary Roselin Nittala ( $\nabla$ mnittala@umc.edu ) \\ University of Mississippi Medical Center https://orcid.org/0000-0002-9755-5672 \\ Eswar K Mundra \\ University of Mississippi Medical Center
}

\section{Satyaseelan Packianathan}

University of Mississippi Medical Center

\section{Divyang Mehta}

University of Mississippi Medical Center

\section{Maria L Smith}

University of Mississippi Medical Center

\section{William C Woods}

University of Mississippi Medical Center

\section{Shawn A McKinney}

University of Mississippi Medical Center

\section{Barbara S Craft}

University of Mississippi Medical Center

Srinivasan Vijayakumar ( $\square$ svijayakumar@umc.edu )

University of Mississippi Medical Center

\section{Research article}

Keywords: Breast cancer, racial disparities, Will Roger's phenomenon

Posted Date: July 28th, 2020

DOI: https://doi.org/10.21203/rs.3.rs-48135/v1

License: (c) (i) This work is licensed under a Creative Commons Attribution 4.0 International License.

Read Full License 
The Will Rogers phenomenon, Breast Cancer and Race

Running Title: The Will Rogers phenomenon, Breast Cancer and Race

Mary R. Nittala, DrPH ${ }^{1}$, Eswar K. Mundra MD ${ }^{1}$, S. Packianathan, MD ${ }^{1}$, Divyang Mehta, MD ${ }^{1}$, Maria L. Smith, MSN, NPC ${ }^{1}$, William C. Woods, MSN, NPC ${ }^{1}$, Shawn McKinney, MD², Barbara S. Craft, $\mathrm{MD}^{3}$, Srinivasan Vijayakumar, $\mathrm{MD}^{1}$.

Departments of Radiation Oncology ${ }^{1}$; Surgery ${ }^{2}$; Medicine ${ }^{3}$; University of Mississippi Medical Center, Jackson, MS, USA.

\section{Corresponding Author:}

Name:

Address:

Phone:

Fax:

Email:

Or

Name:

Address:

Phone:

Fax:

Email:
Dr. Srinivasan Vijayakumar 350 West Woodrow Wilson Jackson, MS 39213 601-815-6886/ 409-457-7827 601-815-1846

svijayakumar@umc.edu
Dr. Mary R Nittala 350 West Woodrow Wilson Jackson, MS 39213 601-984-2562/ 601-622-3166 601-815-1846

mnittala@umc.edu 


\section{ABSTRACT}

Background: The Will Rogers phenomenon [WRP] describes an apparent improvement in outcome for patients' group due to tumor grade reclassification. Staging of cancers is important to select appropriate treatment and to estimate prognosis. The WRP has been described as one of the most important biases limiting the use of historical cohorts when comparing survival or treatment. The main purpose of this study is to assess whether the WRP exists with the move from the AJCC $7^{\text {th }}$ to AJCC $8^{\text {th }}$ edition in breast cancer [BC] staging, and if racial differences are manifested in the expression of the WRP.

Methods: This is a retrospective analysis of 300 BC women (2007- 2017) at an academic medical center. Overall survival [OS] and disease-free survival [DFS], estimated by KaplanMeier analysis. Bi and multi-variate Cox regression analyses, used to identify racial factors associated with outcomes.

Results: Our patient cohort included 30.3\% Caucasians [C] and 69.7\% African-Americans [AA]. Stages I, II, III, and IV were $46.2 \%, 26.3 \%, 23.1 \%$, and $4.4 \%$ of C; $28.7 \%, 43.1 \%, 24.4 \%$, and $3.8 \%$ of AA respectively, in anatomic staging ( $\mathrm{p}=0.043)$. In prognostic staging, $52.8 \%, 18.7 \%$, $23 \%$, and $5.5 \%$ were $\mathrm{C}$ while $35 \%, 17.2 \%, 43.5 \%$, and $4.3 \%$ were AA, respectively $(\mathrm{p}=0.011)$. A total of C (45.05\% vs. 47.85\%) AA, upstaged. C (16.49\% vs. 14.35\%) AA, down-staged. Remaining, $38.46 \%$ and $37.79 \%$ patients had their stages unchanged.

With a median follow-up of 54 months, the AA patients showed better stage-by-stage 5-year OS rates using $8^{\text {th }}$ edition compared to the $7^{\text {th }}$ edition $(p=0.000)$. Among the $C$, those who were stage IIIA in the $7^{\text {th }}$ but became stage IB in the $8^{\text {th }}$ had a better prognosis than stages IIA and IIB in the $8^{\text {th }}(\mathrm{p}=0.000)$. The $8^{\text {th }}$ showed complex results $(\mathrm{p}=0.176)$ compared to DFS estimated using the $7^{\text {th' }} \mathrm{s}(\mathrm{p}=0.004)$.

Conclusion: The WRP exists with significant variability in the move from the AJCC $7^{\text {th }}$ to the $8^{\text {th }}$ edition in BC staging (both $\mathrm{C}$ and AA patients). We suggest that caution needs to be exercised when results are compared across staging systems to account for the WRP in the interpretation of the data.

Key words: Breast cancer, racial disparities, Will Roger's phenomenon 


\section{BACKGROUND}

Breast cancer is the most frequently diagnosed cancer in the world and the second leading cause of death in females [1]. African- American women have an increased rate of early disease onset and a high mortality rate than any other racial group [2, 3]. Socioeconomic factor plays a major role in this disease disparity along with tumor biology or genetics [3, 4]. Cancer staging is an important tool to predict disease progression and for individual treatment design [5]. In 1959, the American Joint Committee on Cancer (AJCC), developed the TNM staging system, eight editions of the AJCC Cancer staging have been published since then $[6,7]$.

Breast cancer has been staged using AJCC TNM staging based on anatomic factors like the extent of the primary tumor $(\mathrm{T})$, the status of adjacent nodes $(\mathrm{N})$, and the presence of distant metastasis (M) [8]. However some reports have suggested that the $7^{\text {th }}$ edition staging do not stratify patients accurately about the prognosis [9-12].

The Will Rogers phenomenon is used to describe the effect of the "stage migration" in patients where the stage-specific survival improved composed to an earlier cohort. Over the past decades, the scientific developments led to a better understanding of breast cancer according to the expression of estrogen receptor (ER), progesterone receptor (PR), human epidermal growth factor receptor 2 (HER2) and proliferation marker (Ki-67) [6, 13, 14]. The close relationship of these receptors with the disease prognosis, treatment selection, and response to the treatment pose a challenge to the $7^{\text {th }}$ AJCC cancer staging criteria for breast cancer. The American Society of Clinical Oncology (ASCO) [15], European Group on Tumor Markers (EGTM) [16], and the National Comprehensive Cancer Network (NCCN) [17] recommend the determination of ER, PR, and HER2 status for prognosis and treatment planning in all breast cancer patients. In addition to the traditional anatomic factors, the new $8^{\text {th }}$ edition of the AJCC TNM classification for breast cancer incorporates grade, ER, PR, HER2, and multigene testing [18].

Controversy persists how accurately the current $8^{\text {th }}$ edition staging system can predict the breast cancer prognosis. The ability to evaluate the high-risk patients and cancer-related mortality is of great importance to treatment and follow up decisions [12, 19]. The primary objective of this retrospective study was to validate the prognostic value of the AJCC $8^{\text {th }}$ edition staging system compared to the previous AJCC $7^{\text {th }}$ staging system and its association with race and overall survival (OS) using a single institute breast cancer research database.

\section{MATERIALS \& METHODS}

\section{Study design and participants}

This retrospective study includes a total of 376 breast cancer women diagnosed and treated between 2007 and 2017 at the University of Mississippi Medical Center (UMMC), Jackson, Mississippi, USA. Institutional review board approval obtained and a browser-based database tool, research electronic data capture (RedCap) was used to gather and store the patient's information in password-protected computers. Seventy-six with unknown pathology staging, other races (other than Caucasians [C] or African Americans [AA]) and ductal carcinoma in situ 
were excluded from the study so a total of 300 breast cancer women were included in this analysis (shown in Fig.1).

\section{Data collection}

Epidemiological, clinical, demographic, treatment and outcome data was obtained from RedCap. Patients were stratified by race according to the $7^{\text {th }}$ AJCC anatomic staging system and the $8^{\text {th }}$ AJCC prognostic staging system. The following patient's characteristics were included: date of diagnosis, age, race, body mass index (BMI), tumor grade, and survival months. All data was collected, checked, analyzed, and interpreted by the postdoc research fellow (MN).

\section{Definitions}

The Will Rogers phenomenon refers to the "improved" survival of patients with cancer or other diseases by either reclassifying them into different prognostic groups, recognizing subtle disease manifestations, or by using diagnostic modalities that allow the disease to be diagnosed at an earlier stage. Disease-free survival (DFS), defined as the number that predicts the chances of staying free of disease or cancer after a particular treatment. Overall survival (OS), defined by the number of days from the date of initial diagnosis until the date of death/ the last contact. The censored cases defined as the patients without death at the time of the last follow up

\section{Statistical Analysis}

Kaplan-Meier method was used to estimate the OS rates and the univariate significance of differences among survival curves calculated by the log-rank test. The co-variables associated with the OS and DFS were determined by the bi and multivariate Cox regression model. Hazards ratio (HR) was used to estimate time to event outcome with associated $95 \%$ confidence intervals (CIs) and $\mathrm{P}$ values $\leq 0.05$ were considered statistically significant. Data was analyzed using SPSS 24.0 software (IBM, Armonk, NY, USA).

\section{Sample Size analysis:}

$\alpha($ two tailed $)=0.05$ Threshold probability for rejecting the null hypothesis. Type 1 error rate $\mathrm{B}=0.200 \quad$ Probability of failing to reject the null hypothesis under the alternative hypothesis. Type II error rate

$\mathrm{q} 1=0.199 \quad$ Proportion of subjects that are in Group 1

$\mathrm{q} 0=0.801 \quad$ Proportion of subjects that are in Group 0

$\mathrm{RH}=0.667 \quad$ Relative hazard (Group1/ Group 0)

The standard normal deviate for $\alpha=Z_{\alpha}$ (for $95 \%$ confidence $)=1.960$

The standard normal deviate for $\beta=Z_{\beta}\left(80 \%\right.$ power $\left.Z_{0.80}\right)=0.842$

$$
\begin{aligned}
& A=\left(Z_{\alpha}+Z_{\beta}\right)^{2}=7.849 \\
& B=(\log (R H))^{2} q_{0} q_{1}=0.026 \\
& \text { Sample Size }=\left(Z_{\alpha}+Z_{\beta}\right)^{2} /(\log (R H))^{2} q_{0} q_{1} \\
& =7.849 / 0.026=300
\end{aligned}
$$

Therefore, a sample size of $n=300$ will ensure that a two-sided test with $\alpha=0.05$ has $80 \%$ power to detect the factors affecting the survival in our study population. 


\section{RESULTS}

\section{Patient Characteristics}

A total of 300 primary breast cancer patients treated at UMMC between 2007 and 2017 were identified. Out of 300 patients, 91 (30.3\%) were C and 209 (69.7\%) AA. The baseline characteristics of these patients (Table 1) had a median age of 62 years [y] (range, 34 to $92 \mathrm{y}$ ) and AA women were diagnosed with breast cancer at a young age compared to $\mathrm{C}(32.6 \%$ vs. $19.8 \% ; \mathrm{p}=0.025$ ). AA breast cancer women presented were with higher BMI levels compared to $\mathrm{C}(60.3 \%$ vs. $41 \%$; $\mathrm{p}=0.007)$.

When the receptor characteristics of this study population measured, the most common subtype was ER+/PR+/HER2-, accounting $33.3 \%$ of $\mathrm{C}$ and $66.7 \%$ of AA respectively ( $\mathrm{p}=0.336$ ). The AA were significantly less likely to have positive tumor receptors of ER $(65.6 \%$ vs. $74.7 \%)$ and PR (48.3\% vs. $64.8 \%)$ compared to C women. Stages I, II, III, and IV accounted for $46.2 \%$, $26.3 \%, 23.1 \%$, and $4.4 \%$ of $\mathrm{C}$ and $28.7 \%, 43.1 \%, 24.4 \%$, and $3.8 \%$ of AA respectively, in $7^{\text {th }}$ AJCC anatomic staging $(\mathrm{p}=0.043)$. In $8^{\text {th }}$ AJCC prognostic staging, 52.8\%, 18.7\%, 23\%, and $5.5 \%$ were $\mathrm{C}$ while $35 \%, 17.2 \%, 43.5 \%$, and $4.3 \%$ were AA, respectively ( $\mathrm{p}=0.011$ ). AA women were significantly more likely to be diagnosed at a later stage, notably at stage IIB and higher in $7^{\text {th }}$ AJCC anatomic staging and notably at stage IIIA and higher in $8^{\text {th }}$ AJCC prognostic staging.

A total number of $41 \mathrm{C}(45.1 \%)$ upstaged compared to $100 \mathrm{AA}(47.9 \%)$ patients. Fifteen C patients $(16.5 \%)$ and 30 AA patients $(14.4 \%)$ were down-staged. Of the remainder, $35 \mathrm{C}(38.5$ $\%)$ and $79 \mathrm{AA}(37.8 \%)$ patients had their stages unchanged $(\mathrm{P}=0.859)$. The greatest changes in stage for $8^{\text {th }}$ AJCC were in stage IB (rise by $19.3 \%$ ), IA (drop by 13\%), IIA (drop by $12.3 \%$ ), and IIB (drop by 8\%) compared to the $7^{\text {th }}$ AJCC anatomic staging. The stage IB changes resulted from two components: the stage IIA (12.3\%), IIB (8\%), downstages to IB and stage IA (13\%) upstaged to IB from the $7^{\text {th }}$ AJCC anatomic staging system to the $8^{\text {th }}$ AJCC prognostic staging system.

\section{Kaplan-Meier curves for Overall Survival and Disease-Free Survival}

Univariate analysis by Kaplan-Meier demonstrated that $C$ patients with stage IIIA had the worst prognosis than those with stage IIIB within the $7^{\text {th }}$ AJCC anatomic staging system $(64.3 \%$ vs.85.9\%; $p=0.000$ ) at a median follow-up of 58 months (range 4 to 235 months) (shown in Fig. 2).

The five-year OS rates by stage (Table 2) indicate that the AA patients showed better stage -bystage rates using $8^{\text {th }}$ edition compared to the $7^{\text {th }}$ edition, suggesting a manifestation of the WRP. Among the $\mathrm{C}$ patients, those who were stage IIIA in the $7^{\text {th }}$ edition but became stage IB in the $8^{\text {th }}$ had a better prognosis than stages IIA and IIB in the $8^{\text {th }}$ edition $(\mathrm{p}=0.000)$. For AA patients, stage IIIA, IIIB, IIIC, and IV $(93.3 \%, 74 \%, 68.1 \%$, and $66.7 \%)$ all demonstrated better prognoses in the $8^{\text {th }}$ edition when compared to the $7^{\text {th }}$ edition $(\mathrm{p}=0.000)$.

In terms of DFS, the $8^{\text {th }}$ edition's clinical staging showed complex results $(\mathrm{p}=0.176)$ compared to DFS estimated using the $7^{\text {th' }} \mathrm{s}$ anatomic staging system $(\mathrm{p}=0.004)$ (Table 2$)$. For $\mathrm{C}$ patients, 
Breast Cancer Patients treated at UMMC from 2007 to 2017

$(n=376)$

Include:

Caucasian $(n=91)$

- $\quad E R, P R, H E R 2$ status known $(n=83)$

- $\quad E R, P R, H E R 2$ status un known $(n=8)$

African - American ( $n=209)$

- $\quad E R, P R, H E R 2$ status known $(n=202)$

- $\quad E R, P R, H E R 2$ status unknown $(n=7)$

Exclude:

Ductal carcinoma in situ $(n=45)$

Other races $(n=12)$

Paget's ( $n=2)$

Tumor grade unknown $(n=17)$

Breast Cancer Patients used for validation of AJCC $8^{\text {th }}$ edition of TNM classification $(n=300)$

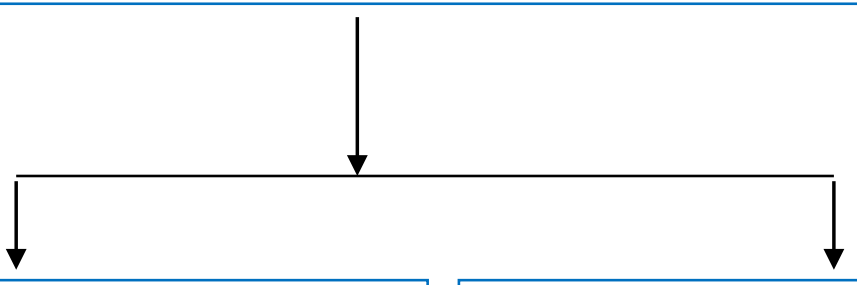

Caucasian Breast Cancer Patients ( $n=91 ; 30.3 \%)$

- Upstaged $(n=41 ; 45.5 \%)$

- $\quad$ Down staged $(n=15 ; 16.5 \%)$

- Unchanged $(n=35 ; 38.5 \%)$
African- American Breast Cancer Patients ( $n=209 ; 69.7 \%$ )

- Upstaged ( $n=100 ; 47.8 \%)$

- $\quad$ Down staged $(n=30 ; 14.4 \%)$

- Unchanged $(n=79 ; 37.8 \%)$

Fig. 1- Flow chart for Breast Cancer Patients Cohort selection. UMMC, University of Mississippi Medical Center; ER, estrogen receptor; PR, progesterone receptor, HER2, human epidermal growth factor receptor 2 ; n, number; \%, percentage. 


\begin{tabular}{|c|c|c|c|c|}
\hline \multicolumn{5}{|c|}{ Table 1 - Baseline Characteristics of included Breast Cancer Patients $(n=300)$} \\
\hline & $C(n=91) 30.3 \%$ & $A A(n=209) 69.7 \%$ & All Patients $(n=300) 100 \%$ & p-Value \\
\hline \multicolumn{5}{|l|}{ Age } \\
\hline$\leq 39$ & $2(2.2 \%)$ & $6(2.9 \%)$ & $8(2.7 \%)$ & \multirow[t]{4}{*}{0.074} \\
\hline 40- 59 & $16(17.6 \%)$ & $62(29.7 \%)$ & $78(26.0 \%)$ & \\
\hline 60- 79 & $51(56.0 \%)$ & $110(52.6 \%)$ & $161(53.7 \%)$ & \\
\hline$\geq 80$ & $22(24.2 \%)$ & $31(14.8 \%)$ & $53(17.7 \%)$ & \\
\hline \multicolumn{5}{|l|}{ BMI } \\
\hline Normal & $15(16.5 \%)$ & $29(13.9 \%)$ & $44(14.7 \%)$ & \multirow[t]{4}{*}{0.058} \\
\hline Overweight & $36(39.6 \%)$ & $54(25.8 \%)$ & $90(30.0 \%)$ & \\
\hline Obese & $30(33.0 \%)$ & 90 (43.1\%) & $120(40.0 \%)$ & \\
\hline Morbidity & $10(11.0 \%)$ & $36(17.2 \%)$ & $46(15.3 \%)$ & \\
\hline \multicolumn{5}{|l|}{ Grade } \\
\hline I & $29(32.2 \%)$ & 40 (19.1\%) & $69(23.0 \%)$ & \multirow{3}{*}{0.035} \\
\hline II & $32(35.6 \%)$ & 75 (35.9\%) & 107 (35.7\%) & \\
\hline III- IV & $30(33.0 \%)$ & $94(45.0 \%)$ & 124 (41.3\%) & \\
\hline \multicolumn{5}{|l|}{ ER status } \\
\hline Positive & $68(74.7 \%)$ & 137 (65.6\%) & 205 (68.3\%) & \multirow[t]{3}{*}{0.004} \\
\hline Negative & $20(22.0 \%)$ & $72(34.4 \%)$ & $92(30.7 \%)$ & \\
\hline Unknown & $3(3.3 \%)$ & $0(0.0 \%)$ & $3(1.0 \%)$ & \\
\hline \multicolumn{5}{|l|}{ PR status } \\
\hline Positive & $59(64.8 \%)$ & 101 (48.3\%) & 160 (53.3\%) & \multirow[t]{3}{*}{0.015} \\
\hline Negative & $30(33.0 \%)$ & $106(50.7 \%)$ & $136(45.3 \%)$ & \\
\hline Unknown & $2(2.2 \%)$ & $2(1.0 \%)$ & $4(1.3 \%)$ & \\
\hline \multicolumn{5}{|l|}{ HER2 status } \\
\hline Positive & $26(28.6 \%)$ & 35 (16.7\%) & $61(20.3 \%)$ & \multirow[t]{3}{*}{0.053} \\
\hline Negative & $62(68.1 \%)$ & 169 (80.9\%) & 231 (77.0\%) & \\
\hline Unknown & $3(3.3 \%)$ & $5(2.4 \%)$ & $8(2.7 \%)$ & \\
\hline \multicolumn{5}{|c|}{$7^{\text {th }}$ AJCC TNM stage } \\
\hline Stage IA & $42(46.2 \%)$ & $60(28.7 \%)$ & 102 (34.0\%) & \multirow[t]{7}{*}{0.043} \\
\hline Stage IIA & $15(16.5 \%)$ & $54(25.8 \%)$ & $69(23.0 \%)$ & \\
\hline Stage IIB & $9(9.9 \%)$ & $36(17.2 \%)$ & 45 (15.0\%) & \\
\hline Stage IIIA & $7(7.7 \%)$ & $20(9.6 \%)$ & $27(9.0 \%)$ & \\
\hline Stage IIIB & $11(12.1 \%)$ & $17(8.1 \%)$ & $28(9.3 \%)$ & \\
\hline Stage IIIC & $3(3.3 \%)$ & $14(6.7 \%)$ & $17(5.7 \%)$ & \\
\hline Stage IV & $4(4.4 \%)$ & $8(3.8 \%)$ & $12(4.0 \%)$ & \\
\hline \multicolumn{5}{|c|}{$8^{\text {th }}$ AJCC TNM stage } \\
\hline Stage IA & $25(27.5 \%)$ & $38(18.2 \%)$ & $63(21.0 \%)$ & \multirow[t]{8}{*}{0.011} \\
\hline Stage IB & $23(25.3 \%)$ & $35(16.7 \%)$ & $58(19.3 \%)$ & \\
\hline Stage IIA & $8(8.8 \%)$ & $24(11.5 \%)$ & $32(10.7 \%)$ & \\
\hline Stage IIB & $9(9.9 \%)$ & $12(5.7 \%)$ & $21(7.0 \%)$ & \\
\hline Stage IIIA & $4(4.4 \%)$ & 30 (14.4\%) & $34(11.3 \%)$ & \\
\hline Stage IIIB & $3(3.3 \%)$ & $26(12.4 \%)$ & $29(9.7 \%)$ & \\
\hline Stage IIIC & $14(15.4 \%)$ & $35(16.7 \%)$ & 49 (16.3\%) & \\
\hline Stage IV & $5(5.5 \%)$ & $9(4.3 \%)$ & $14(4.7 \%)$ & \\
\hline
\end{tabular}

$\mathrm{C}=$ Caucasians, $\mathrm{AA}=$ African American, $\mathrm{BMI}=$ body mass index, $\mathrm{ER}=$ estrogen receptor, $\mathrm{PR}=$ progesterone receptor, HER2= human epidermal growth factor receptor 2, AJCC $=$ American Joint Committee on Cancer, $\mathrm{n}=$ Number. 

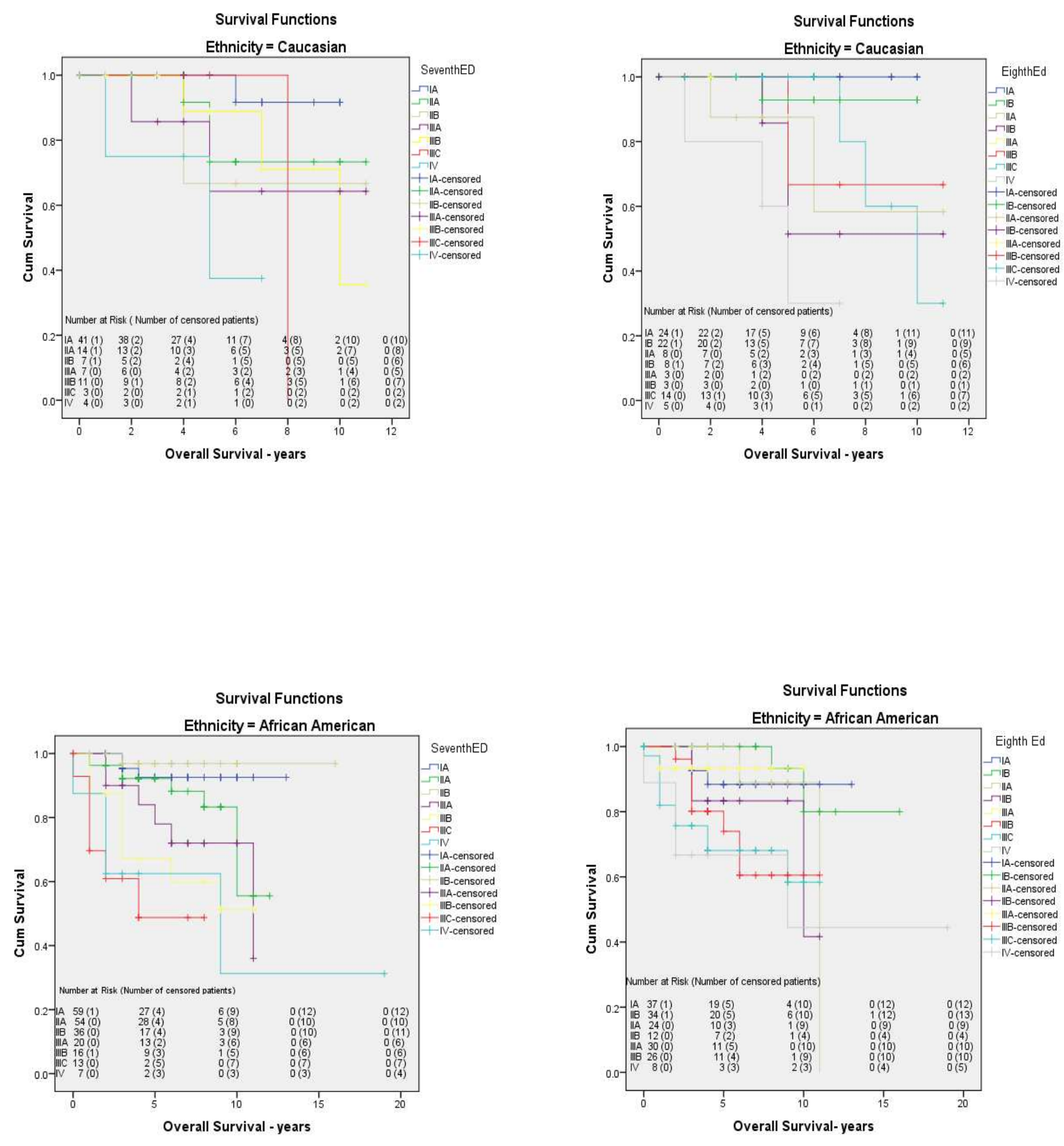

Fig. 2 - The Kaplan- Meier survival curves (years) for AJCC $7^{\text {th }}$ anatomic staging and AJCC $8^{\text {th }}$ prognostic staging for Caucasian and African- American women diagnosed with breast cancer. 
stages IA, IB, IIB, and IIIC $(31.1 \%, 31.9 \%, 31.1 \%$, and $27.3 \%)$ all recorded better DFS when using the $8^{\text {th }}$ edition while for AA patients, only those with stages IB and IIIC $(49.2 \%$ and $45.5 \%$ ) showed better DFS in the $8^{\text {th }}$ edition compared to the $7^{\text {th }}$ (shown in Fig.3)
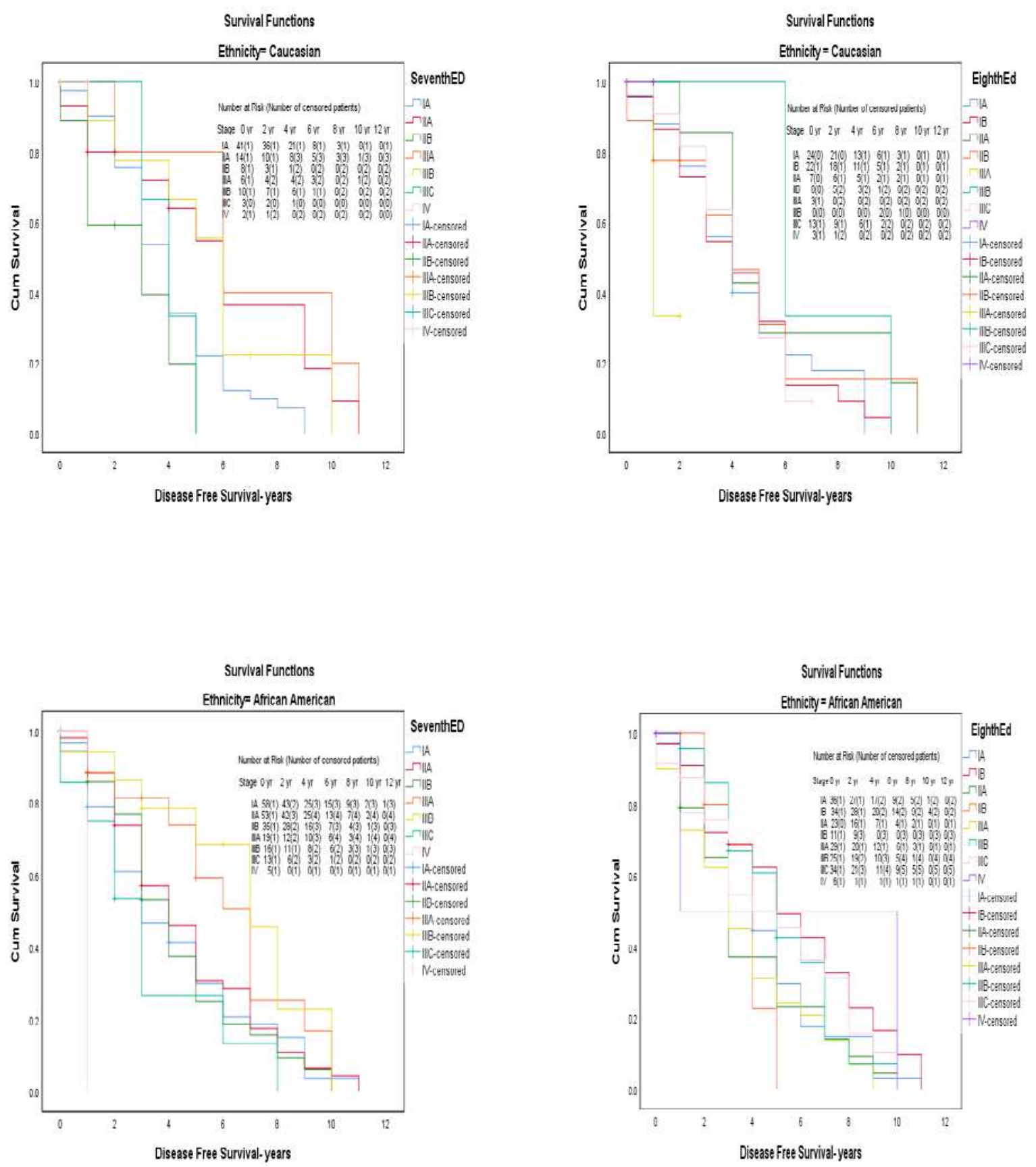

Fig.3 - The Kaplan- Meier disease-free survival curves (years) for AJCC $7^{\text {th }}$ anatomic staging and AJCC $8^{\text {th }}$ prognostic staging for Caucasian and African- American women diagnosed with breast cancer. 


\begin{tabular}{|c|c|c|c|c|c|c|c|c|}
\hline & \multicolumn{4}{|c|}{ 5-year Overall Survival } & \multicolumn{4}{|c|}{ 5-year Disease free Survival } \\
\hline & \multicolumn{2}{|c|}{ Caucasian } & \multicolumn{2}{|c|}{ African American } & \multicolumn{2}{|c|}{ Caucasian } & \multicolumn{2}{|c|}{ African American } \\
\hline & AJCC- $7^{\text {th }}$ Ed & AJCC $-8^{\text {th }} \mathrm{Ed}$ & AJCC- $7^{\text {th }}$ Ed & AJCC $-8^{\text {th }} \mathrm{Ed}$ & AJCC- $7^{\text {th }}$ Ed & AJCC $-8^{\text {th }}$ Ed & AJCC-7th Ed & AJCC $-8^{\text {th }} E d$ \\
\hline Stage IA & $91.7 \%$ & $100.0 \%$ & $92.5 \%$ & $88.4 \%$ & $22.0 \%$ & $31.1 \%$ & $30.1 \%$ & $29.7 \%$ \\
\hline Stage IB & .. & $92.9 \%$ & .. & $100.0 \%$ & .. & $31.9 \%$ & .. & $49.2 \%$ \\
\hline Stage IIA & $73.3 \%$ & $58.3 \%$ & $88.2 \%$ & $88.9 \%$ & $54.9 \%$ & $28.6 \%$ & $30.7 \%$ & $23.3 \%$ \\
\hline Stage IIB & $66.7 \%$ & $51.4 \%$ & $96.9 \%$ & $83.3 \%$ & $0.0 \%$ & $31.1 \%$ & $25.1 \%$ & $0.0 \%$ \\
\hline Stage IIIA & $64.3 \%$ & .. & $78.0 \%$ & $93.3 \%$ & $40.0 \%$ & - & $59.2 \%$ & $24.2 \%$ \\
\hline Stage IIIB & $85.9 \%$ & $66.7 \%$ & $59.8 \%$ & $74.0 \%$ & $55.6 \%$ & $33.3 \%$ & $68.6 \%$ & $42.6 \%$ \\
\hline Stage IIIC & $0.0 \%$ & $80.0 \%$ & $48.8 \%$ & $68.1 \%$ & $0.0 \%$ & $27.3 \%$ & $13.4 \%$ & $45.5 \%$ \\
\hline Stage IV & $37.5 \%$ & $30.0 \%$ & $31.3 \%$ & $66.7 \%$ & $0.0 \%$ & $0.0 \%$ & $0.0 \%$ & $0.0 \%$ \\
\hline
\end{tabular}

AJCC = American Joint Committee on Cancer, Ed= Edition

\section{Cox Regression Analysis for Overall Survival}

The hazard ratios [HR] comparing racial differences (C vs. AA) about the risk of death was calculated by bivariate Cox regression (Table 3). Regarding BMI, the AA breast cancer patients showed a $23 \%$ decreased risk of mortality (HR 0.72, 95\% CI, 0.52-0.98; $\mathrm{p}=0.039$ ) compared to C patients.

The risk estimates for $7^{\text {th }}$ AJCC staging indicate that AA breast cancer patients showed significant decreased risk for stage IIA (HR 0.23, 95\% CI, 0.09-0.58; $\mathrm{p}=0.002$ ), IIB (HR 0.76, 95\% CI, 0.41-1.38; $\mathrm{p}=0.375$ ), and IIIA (HR 0.23, 95\% CI, 0.07-0.80; $\mathrm{p}=0.020$ ). Followed by increased risk of death for stages IIIB (HR 1.30, 95\% CI, 0.66-2.55; p=0.444), IIIC (HR 1.64, 95\% CI, 0.87-3.08; $\mathrm{p}=0.119$ ), and three times significantly higher risk of death for stage IV (HR $3.38,95 \% \mathrm{CI}, 1.64-6.94 ; \mathrm{p}=0.001$ ), compared to the $\mathrm{C}$ breast cancer patients.

The risk estimates for $8^{\text {th }}$ AJCC staging indicate that AA breast cancer patients showed significant decreased risk for stage IB (HR 0.34, 95\% CI, 0.12-0.96; p=0.042), IIA (HR 0.32, 95\% CI, 0.11-0.91; $\mathrm{p}=0.033$ ); decreased risk for stage IIB (HR 0.83, 95\% CI, 0.33-2.07; $\mathrm{p}=0.680$ ) and stage IIIB (HR 0.45, 95\% CI, 0.13-1.60; $\mathrm{p}=0.222$ ). Showed increased risk of death for stages IIIA (HR 1.81, 95\% CI, 0.83-3.94; $\mathrm{p}=0.130$ ), stage IIIC (HR 1.84, 95\%CI, 0.95-3.59; $\mathrm{p}=0.070$ ), and twice significantly higher risk of death for stage IV (HR 1.96, 95\% CI, 1.11-3.47; $\mathrm{p}=0.020$ ), compared to the $\mathrm{C}$ breast cancer patients.

The multivariate Cox regression was built in which all the significant variables, BMI, $7^{\text {th }}$ AJCC staging and $8^{\text {th }}$ AJCC staging were added in the model (Table 3). AA breast cancer patients were twice the increased risk of death with higher BMI compared to $\mathrm{C}$ patients. All the stages in the $7^{\text {th }}$ AJCC staging group showed decreased risk for AA except for stage IV, which showed twice the risk compared to $\mathrm{C}$ patients. All the stages in the $8^{\text {th }}$ AJCC staging group showed decreased risk for AA patients compared to $\mathrm{C}$. It is interesting to notice that none of the variables showed any statistical significance in the multivariate analyses. 


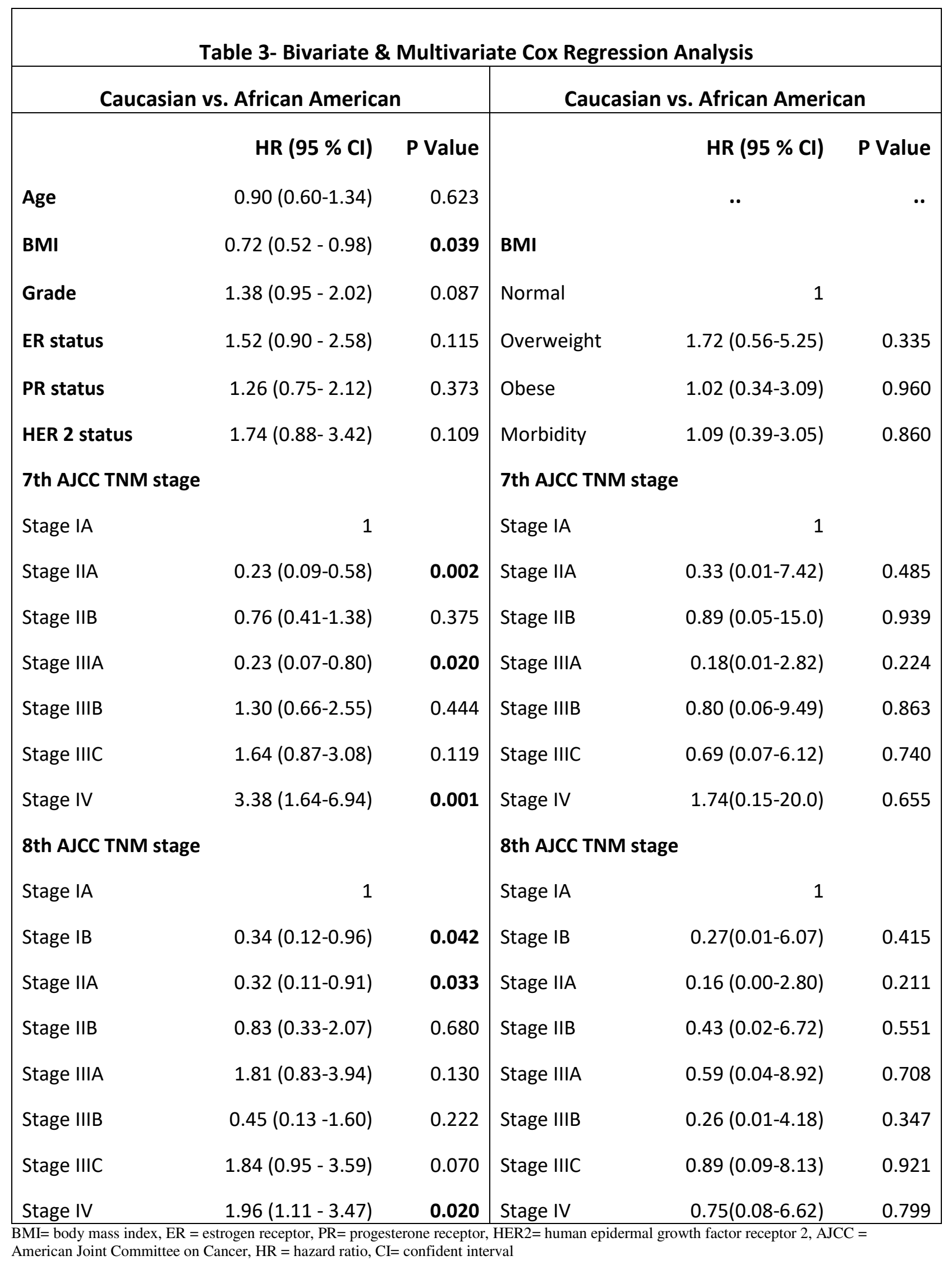




\section{DISCUSSION}

The Will Rogers phenomenon refers to the "improved" survival of patients with cancer or other diseases by either reclassifying them into different prognostic groups, recognizing subtle disease manifestations, or by using diagnostic modalities that allow the disease to be diagnosed at an earlier stage [20]. In other words, the Will Rogers phenomenon describes an apparent improvement in outcome for a group of patients with no actual improvement for any individual patient but due to tumor stage or tumor grade reclassification. This phenomenon is based on a remark made by the humorist-philosopher Will Rogers "When the Okies left Oklahoma and moved to California, they raised the average intelligence level in both states"[20, 21]. Feinstein AR, et al first used the term Will Rogers phenomenon to describe the effect of the "stage migration" observed in 1977 lung cancer patients cohort [21], the stage-specific survival improved in a 1997 cohort compared to an earlier cohort [19]. Feinstein AR, et al suggested that the improvement of stage-specific OS rates among lung cancer patients is a statistical artifact, and can be resolved with proper intensive scientific attention [21]. The study by Chee KG, et al also supported the notion that stage migration is responsible for the improvement of survival for patients with stage III and stage IV non-small cell lung cancer, demonstrating that the Will Rogers phenomenon is an important issue to consider when interpreting the clinical studies results [22].

Woodward WA and her colleagues reported that 5-10 survival rates for stage II breast cancer women according to 1988 guidelines were 72 and 53\%, respectively. The same women showed 86 and $75 \%$ OS when classified according to the 2003 guidelines. They also reported that $31 \%$ of women with 1988- diagnosed stage IIa disease, $54 \%$ of stage IIb and $38 \%$ of stage IIIa, moved into higher stage groups, implying that comparisons of survival data between patients staged with different systems will be inaccurate and must include tumor characteristics that will result in significant changes in reported outcome by stage $[23,24]$. Their study concluded that the revised AJCC staging guidelines raised significant improvements in stage-specific survival of breast cancer patients and careful attention be given to the Will Rogers phenomenon for accurate decision making for improved new treatment strategies [24].

Kim, et al reported that breast cancer patient cohorts staged under AJCC5, showed poorer 10year OS who were upstaged under AJCC6, (81 vs. 78\% IIA, 73 vs. 65.4\% IIB, 69.7 vs. 54.8\% IIIA), demonstrating that upstaging reports more accurate disease outcomes and suggested to reevaluate the nodal involvement impact upon new staging system [25]. It is very important to standardize the AJCC staging when comparing the stage at presentation and the stage-specific survival over a time period [19, 23, 25].

Albersten PC, et al reported a decline in the low-grade prostate cancer incidence rate, which seems to be the result of Gleason score reclassification (average upgrade of 0.85 points; $\mathrm{p}<0.001$ ) over the past two decades improving the clinical outcomes ( $26 \%$ reduction in mortality; $\mathrm{p}=0.012$ ) reflecting the Will Rogers phenomenon [26].

The Will Rogers phenomenon is also reported by de Manzoni, et al in melanoma and carcinoma of the stomach with stage migration increased (39.1\%) with the level of nodal involvement (pN1 
tier $3.8 \%$ vs. $50 \%$ in pN3 tier), and with depth of tumor invasion (pT1 class $1.5 \%$ vs. $15.7 \%$ in pT3/pT4 class) [27].

George $\mathrm{S}$, et al reported that stage migration along with biological predetermination is a significant factor in colorectal cancer patient's survival outcomes [28]. Champion GA, et al reported that improved diagnostic imaging will lead to improved stage-specific survival (stage I, III improved $+3 \%$, IV improved $+11 \%$ ) without any change in overall survival in laryngeal cancer patients [29].

We are the first to report a large cohort of AA population with the manifestation of the Will Rogers phenomenon, also the first to report the differences in the Will Rogers phenomenon between AA and C. Ours is one of the many studies documenting Will Rogers phenomenon between AJCC $7^{\text {th }}$ anatomic staging system and AJCC $8^{\text {th }}$ prognostic staging system among breast cancer patients. Shao N, et al demonstrated the $8^{\text {th }}$ AJCC prognostic accuracy to be superior to the anatomic $7^{\text {th }}$ AJCC staging system in breast cancer patients using SEER database. They reported 3-year OS for stage IIIB $(68.5 \%$ vs. $75.5 \%)$ to be inferior to IIIC in $7^{\text {th }}$ AJCC staging system, but this inconsistency was not seen in the $8^{\text {th }}$ AJCC system (85.5\% vs. 69.9\%). Thus concluding higher the patients staged, poorer the prognosis will be seen in the $8^{\text {th }}$ prognostic staging system [11]. Wong RX, et al demonstrated similar findings confirming the prognostic accuracy of $8^{\text {th }}$ AJCC over the $7^{\text {th }}$ AJCC staging system in predicting outcomes among the Asian population. They reported the $8^{\text {th }}$ AJCC prognostic staging system had better 5year cancer-specific survival (0.79 vs. 0.77$)$ compared to the $7^{\text {th }}$ AJCC anatomic staging system [30].

Many studies show that AA women who were diagnosed with breast cancer have a significantly increased risk of death compared with $C$ women [13-15], highlighting the independent predictive nature of the race. Many factors contribute to race-related disparities in breast cancer outcomes $[16,17]$; tumor biology, age, BMI, and AJCC tumor staging $\left(7^{\text {th }} \& 8^{\text {th }}\right)$ may further explain the significant correlation of the race and survival outcomes. Another factor to consider is the Will Rogers phenomenon. The current study reports that AA patients were diagnosed at a younger age with high-grade breast cancer than C (44.6 vs. 23.3\%), and AA breast cancer patients at younger ages with high-grade showed worse survival compared to $\mathrm{C}$. There were also differences in the Will Rogers phenomenon between the races.

The poorer prognosis for obese AA patients has been reported in a previous study [20]; our study confirms the double the risk of death for AA patients whose BMI is at an obese level compared to $C$ patients. Obesity is linked with later tumor stage at the time of diagnosis [19] and poorer survival $[13,20]$; our study reports that about $89 \%$ of AA patients were presented with high tumor grade.

AA women were less likely to have positive hormone receptors (ER/PR/HER2), more likely to have negative hormone receptors, and significant racial differences were noted in histologic categories [14], our study reports similar findings. Shao $\mathrm{N}$ et al reported that the prognostic accuracy of the $8^{\text {th }}$ AJCC staging system to be superior to the $7^{\text {th }}$ AJCC [21], similar findings were reported by the Abdel- Rahman using the SEER research database [22]. Our retrospective study reports, when breast cancer patients restaged from $7^{\text {th }}$ AJCC to $8^{\text {th }}$ AJCC staging system, a 
total percent of C (45.1\% vs. $47.9 \%)$ upstaged, (16.5\% vs. $14.4 \%)$ down-staged and (38.5\% vs. $37 \%$ ) remained unchanged compared to AA patients with no significant difference between races.

In our study, 5-year OS rates by stage indicate that for $\mathrm{C}$ breast cancer patients, IIIC was still inferior to stage IV in the $7^{\text {th }}$ AJCC staging system but this inconsistency was reproduced at IIIB and IV in the $8^{\text {th }}$ AJCC prognostic staging system. Among the AA breast cancer patients, IIA was inferior to stage IIB in the $7^{\text {th }}$ AJCC staging system with no inconsistency (IIA \& IIB) but inconsistent (IIB \& IIIA) in the $8^{\text {th }}$ AJCC prognostic system. Stage IIIA among C patients in the $7^{\text {th }}$ AJCC migrated to IB and have a worse prognosis than IIA or IIB in the $8^{\text {th }}$ AJCC prognostic system. In contrast, IIIA patients among AA patients had better survival than IIA or IIB in the $8^{\text {th }}$ AJCC prognostic system. A similar inconsistency was observed in the 5-year DFS between both races when restaged from $7^{\text {th }}$ AJCC to $8^{\text {th }}$ AJCC.

\section{SUMMARY AND CONCLUSION}

Our analyses suggest that the Will Rogers phenomenon exists in the move from the AJCC $7^{\text {th }}$ to the $8^{\text {th }}$ edition in breast cancer staging in both C and AA patients. However, there were significant variabilities between the races in the extent of their manifestation. We suggest that caution needs to be exercised when results are compared across staging systems in view of the Will Rogers Phenomenon in the interpretation of the data for both Caucasians and African Americans.

\section{LIST OF ABBREVIATIONS}

$\begin{array}{ll}\text { AA } & \text { African- Americans } \\ \text { AJCC } & \text { American Joint Committee on Cancer } \\ \text { ASCO } & \text { The American Society of Clinical Oncology } \\ \text { BC } & \text { Breast Cancer } \\ \text { BMI } & \text { Body Mass Index } \\ \text { C } & \text { Caucasians } \\ \text { CI } & \text { Confident Interval } \\ \text { DFS } & \text { Disease- Free Survival } \\ \text { EGTM } & \text { European Group on Tumor Markers } \\ \text { ER } & \text { Estrogen Receptor } \\ \text { HER2 } & \text { Human Epidermal Growth Factor Receptor } 2 \\ \text { HR } & \text { Hazard Ratio } \\ \text { M } & \text { Distant Metastasis } \\ \text { N } & \text { Adjacent Nodes } \\ \text { NCCN } & \text { National Comprehensive Cancer Network } \\ \text { OS } & \text { Overall Survival } \\ \text { PR } & \text { Progesterone Receptor } \\ \text { RedCap } & \text { Research Electronic Data Capture } \\ \text { T } & \text { Primary Tumor } \\ \text { UMMC } & \text { University of Mississippi Medical Center } \\ \text { WRP } & \text { Will Roger's Phenomenon }\end{array}$




\section{DECLARATIONS}

Statement of Ethics: The subjects (or their parents or guardians) written consent was waived by Health Insurance Portability and Accountability Act (HIPPA) due to the retrospective nature of the study and patient identifiers were removed before extracting the data.

Study Approval: Institutional Review Board (IRB) Approval \#2018-0218

Consent for Publication: Not applicable

Availability of data and Materials: This study does not contain any sequence/ expression data, protein/molecule characterizations, annotations, and taxonomy data to be deposited in a public repository. Patient identifiers were removed before extracting data and will be shared upon reasonable request.

Competing Interests: There is no conflict of interest present for authors relative to this research Funding: This research did not receive any specific grant from funding agencies in the public, commercial or not-for-profit sectors.

Author's Contributions: MN: developed the concept, data collection, data analysis, writing the manuscript, drafting, final revision, editing and submission; EM, DM \& SP: clinical concept; ML \& WW: editing; SK \& BC: clinical management SV: final revision, grammatical check \& editing.

Acknowledgements: Not applicable

\section{REFERENCES:}

1. Siegel RL, Miller KD, Jemal A. Cancer statistics, 2016. CA Cancer j Clin. 2016; 66:7-30.

2. Hassan A, Hussain F, Sohn C, et al. Early onset of breast carcinoma in African American women with poor prognostic factors. Am J Clin Onc. 1999; 22:436.

3. Sineshaw HM, Gaudet M, Ward EM, et al. Association of race/ ethnicity, socioeconomic status, and breast cancer subtypes in the national cancer database (2010-2011). Breast Cancer Res Treat. 2014; 145:753.

4. Coughlin SS. Social determinants of breast cancer risk, stage, and survival. Breast Cancer Res Treat. 2019; 177:537.

5. Edge SB, Compton CC. The American Joint Committee on Cancer: the 7th Edition of the AJCC Cancer Staging Manual and the Future of TNM. Ann Surg Oncol. 2010; 17:14711474.

6. Amin MB, Edge FL, Edge SB, et al. The eighth edition AJCC Cancer Staging Manual: Continuing to build a bridge from a population-based to a more "personalized" approach to cancer staging. CA Cancer J Clin. 2017; 67:93-99.

7. Gluliano AE, Connolly JL, Edge SB, Mittendorf EA, et al. Breast cancer- major changes in the American joint committee on cancer eighth edition cancer staging manual. CA Cancer J Clin. 2017; 67:290-303.

8. Edge SB, Byrd DR, Compton CC, et al. The AJCC Cancer Staging Manual. $7^{\text {th }}$ ed. New York, NY: Springer; 2009. P. 345-376.

9. Veronesi U, Zurrida S, Viale G, et al. Rethinking TNM: a breast cancer classification to guide to treatment and facilitate research. Breast. 2009; 15:291-295. 
10. Veronesi U, Zurrida S, Viale G, et al. Rethinking TNM: classification for treatment decidion making and research. Breast. 2006; 15:3-8.

11. Shao N, Xie C, Shi Y, et al. Comparison of the 7th and 8th edition of American Joint Committee on Cancer (AJCC) staging systems for breast cancer patients: a surveillance, epidemiology and end results (SEER) analysis. Cancer Manag Res. 2019; 11:1433-1442.

12. Kim JY, Lim JE, Jung HH, et al. Validation of the new AJCC eighth edition of the TNM classification for breast cancer with a single-center breast cancer cohort. Breast Cancer Res Treat. 2018; 171:737-745.

13. Lee SB, Sohn G, Kim J, Chung IY, et al. A retrospective prognostic evaluation analysis using the $8^{\text {th }}$ edition of the American Joint Committee on Cancer staging system for breast cancer. Breast Cancer Res Treat. 2018; 169:257-266.

14. Kurundkar A, Gao X, Zhang K, Britt JP, et al. Comparison of AJCC anatomic and clinical prognostic stage groups in breast cancer: analysis of 3322 cases from a single institution. Clin Breast Cancer. 2018; 18:1347-1352.

15. Harris LN, Ismaila N, McShane LM, et al. Use of Biomarkers to Guide Decisions on Adjuvant Systemic Therapy for Women With Early-Stage Invasive Breast Cancer: American Society of Clinical Oncology Clinical Practice Guideline. J Clin Oncol. 2016; 34:1134-1150.

16. Duffy MJ, Harbeck N, Nap M, et al. Clinical use of biomarkers in breast cancer: updated guidelines from the European Group on Tumor Markers (EGTM). Eur J Cancer. 2017; 75:284-298.

17. Gradishar WJ, Anderson BO, Balassanian R, et al. NCCN Guidelines ${ }^{\circledR}$ insights breast cancer, version 1.2017: Featured updates to the NCCN Guidelines. JNCCN. 2017; 15:433-451.

18. Plichta JK, Ren Y, Thomas SM, et al. Implications for breast cancer restaging based on the 8th Edition AJCC staging manual. Ann Surg Epub. 2018.

19. Tan GH, Bhoo-Pathy N, Taib NA, et al. The Will Rogers phenomenon in the staging of breast cancer - does it matter? Cancer Epidemiol. 2015; 39:115-117.

20. Will Rogers phenomenon. (n.d.) Segen's Medical Dictionary. (2011). https://medicaldictionary.thefreedictionary.com/Will+Rogers+phenomenon. Last accessed: March 9, 2020.

21. Feinstein AR, Sosain DM, Wells CK. The Will Rogers phenomenon. Stage migration and new diagnostic techniques as a source of misleading statistics for survival in cancer. $\mathrm{N}$ Engl J Med. 1985; 312:1604-8.

22. Chee KG, Nguyen DV, Brown M, et al. Positron Emission Tomography and Improved Survival in Patients with Lung Cancer: The Will Rogers Phenomenon Revisited. Arch Intern Med. 2008; 168(14):1541-1549.

23. Damaris C: The Will Rogers Phenomenon. Roping the Effects of a New Cancer Staging System. JNCI. 2013; 95:1105-1106.

24. Woodward WA, Strom EA, Tucker SL, et al. Changes in the 2003 American Joint Committee on cancer staging for breast cancer dramatically affect stage-specific survival. J Clini Oncol. 2003; 21:3244-3248.

25. Kim SI, Park BW, Lee KS. Comparison of stage-specific outcome of breast cancer based on 5th and 6th AJCC staging system. J Surg Oncol. 2006; 93:221-227.

26. Albertsen PC, Hanley JA, Barrows GH, et al. Prostate Cancer and the Will Rogers Phenomenon. JNCI. 2005; 97:1248-1253. 
27. de Manzoni G, Verlato G, Roviello F, et al. The new TNM classification of lymph node metastasis minimises stage migration problems in gastric cancer patients. Br J Cancer. 2002; 87:171-174.

28. George S, Primrose J, Talbot R. et al. Will Rogers revisited: prospective observational study of survival of 3592 patients with colorectal cancer according to number of nodes examined by pathologists. Br J Cancer. 2006; 95:841-847.

29. Champion G, Piccirillo J. The impact of computed tomography on pretherapeutic staging in patients with laryngeal cancer: demonstration of the Will Rogers' phenomenon. Head Neck. 2004; 26:972-976.

30. Wong RX, Wong FX, Lim J, et al. Validation of the AJCC $8^{\text {th }}$ prognostic system for breast cancer in an Asian health care settings. Breast. 2018; 4:0960-9776. 


\section{Figures}

Breast Cancer Patients treated at UMMC from 2007 to 2017

$$
\text { ( } n=376)
$$

Include:

Caucasian $(n=91)$

- $\quad E R, P R, H E R 2$ status known $(n=83)$

- $\quad E R, P R, H E R 2$ status un known $(n=8)$

African - American $(n=209)$

- $E R, P R, H E R 2$ status known ( $n=202)$

- $\quad E R, P R, H E R 2$ status unknown $(n=7)$
Exclude:

Ductal carcinoma in situ $(n=45)$

Other races $(n=12)$

Paget's $(n=2)$

Tumor grade unknown $(n=17)$
Breast Cancer Patients used for validation of AJCC $8^{\text {th }}$ edition of TNM classification $(n=300)$

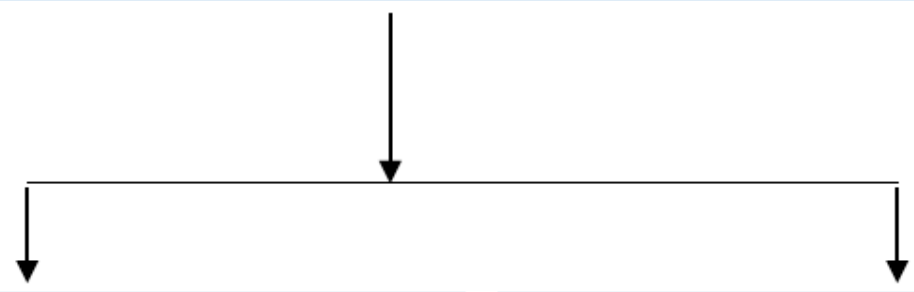

Caucasian Breast Cancer Patients ( $\mathrm{n}=91 ; 30.3 \%$ )

- Upstaged $(n=41 ; 45.5 \%)$

- Down staged $(n=15 ; 16.5 \%)$

- Unchanged $(n=35 ; 38.5 \%)$
African- American Breast Cancer Patients ( $n=209 ; 69.7 \%)$

- Upstaged $(n=100 ; 47.8 \%)$

- Down staged $(\mathrm{n}=30 ; 14.4 \%)$

- Unchanged $(n=79 ; 37.8 \%)$

\section{Figure 1}

Flow chart for Breast Cancer Patients Cohort selection. UMMC, University of Mississippi Medical Center; ER, estrogen receptor; PR, progesterone receptor, HER2, human epidermal growth factor receptor 2; n, number; \%, percentage. 

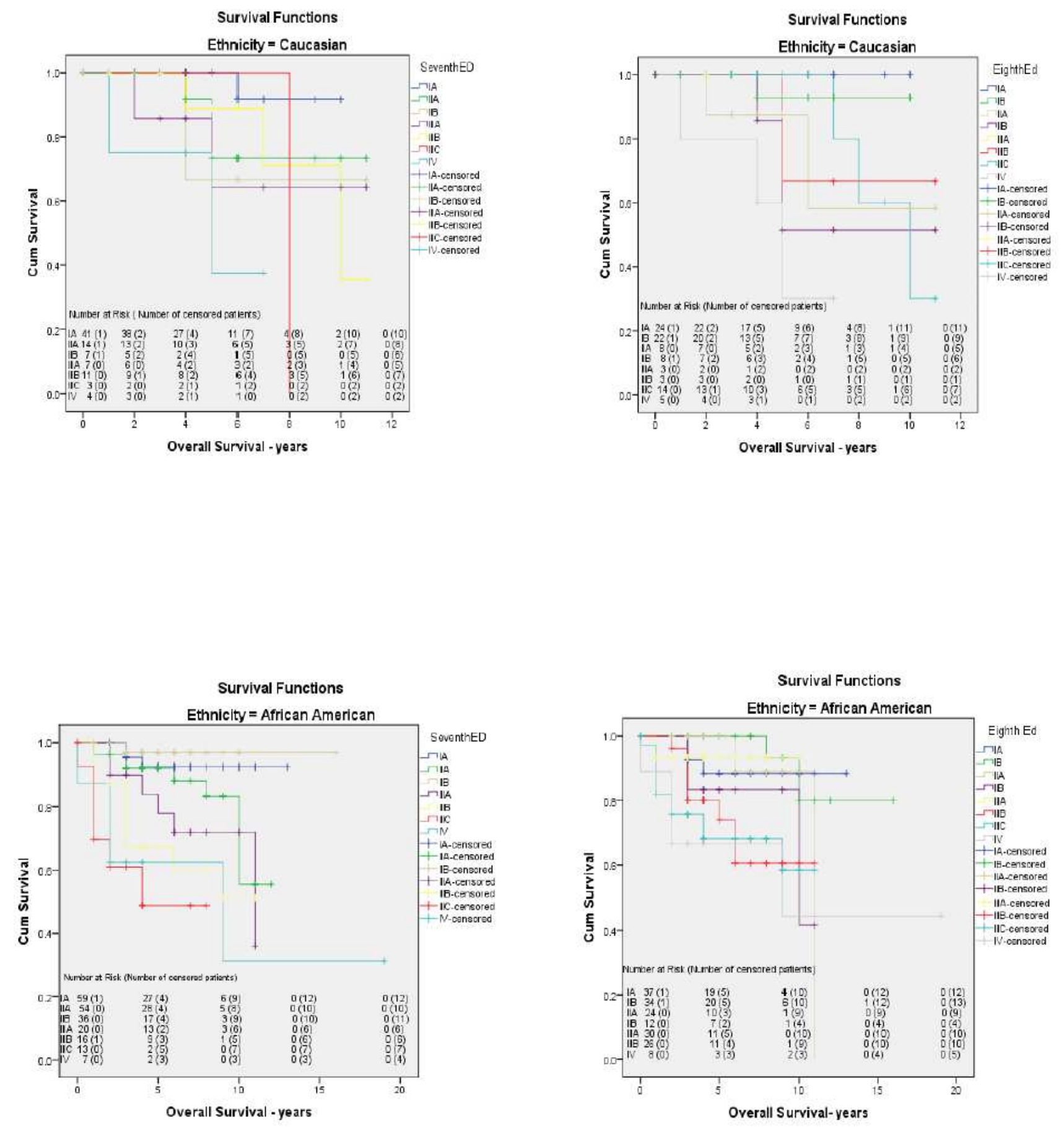

Figure 2

The Kaplan- Meier survival curves (years) for AJCC 7th anatomic staging and AJCC 8th prognostic staging for Caucasian and African- American women diagnosed with breast cancer. 

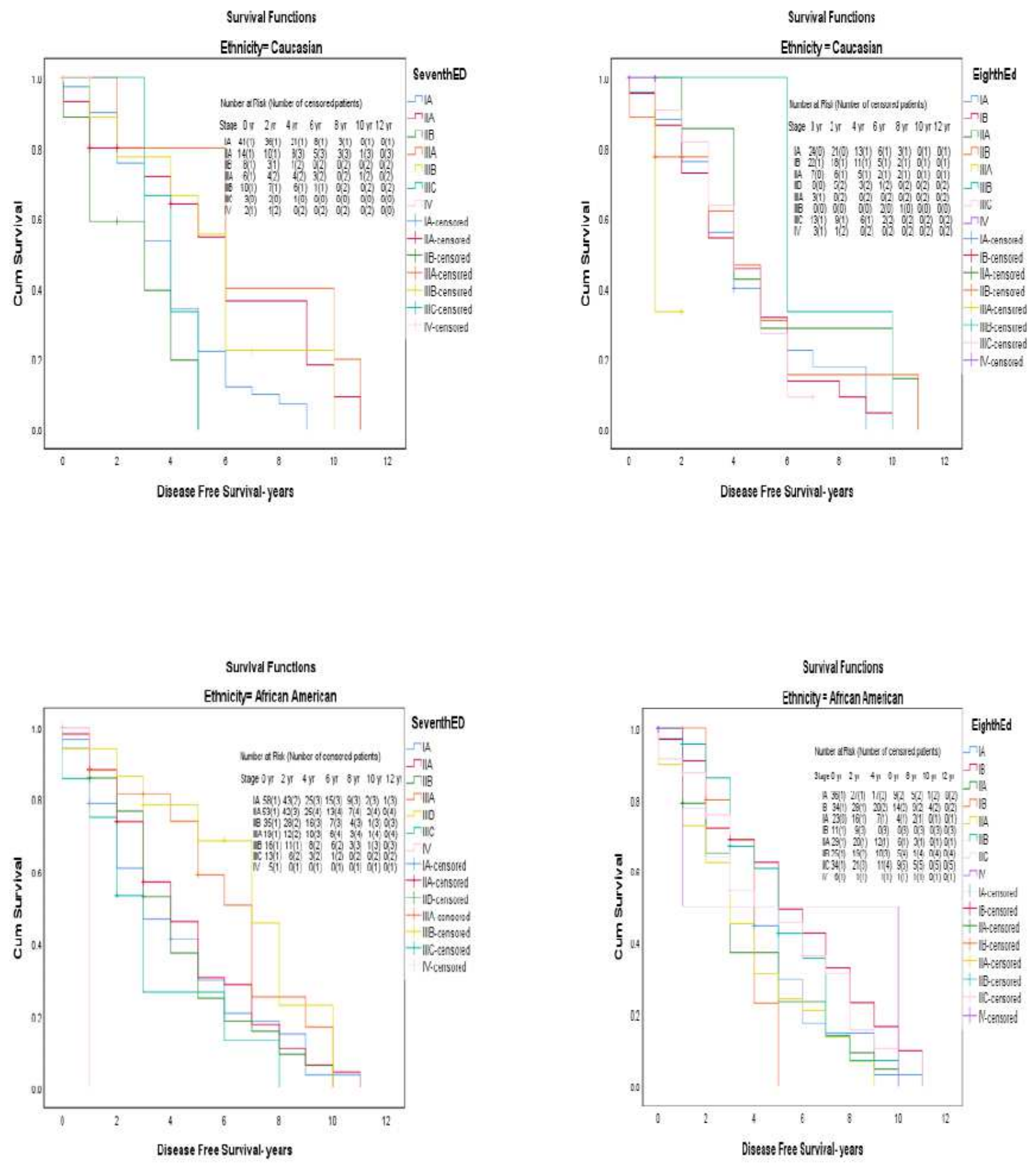

\section{Figure 3}

The Kaplan- Meier disease-free survival curves (years) for AJCC 7th anatomic staging and AJCC 8th prognostic staging for Caucasian and African- American women diagnosed with breast cancer. 